\title{
Italian codified hashtags for weather warning on Twitter - who is really using them?
}

\author{
Valentina Grasso $^{1,2}$, Alfonso Crisci ${ }^{1}$, Marco Morabito ${ }^{1}$, Paolo Nesi ${ }^{3}$, Gianni Pantaleo $^{3}$, Imad Zaza ${ }^{3}$, and \\ Bernardo Gozzini ${ }^{2}$ \\ ${ }^{1}$ Institute of Biometeorology, Italian National Research Council, Via G. Caproni 8, Florence, Italy \\ ${ }^{2}$ LaMMA Consortium, Via Madonna del Piano 10, Sesto Fiorentino (FI), Italy \\ ${ }^{3}$ DISIT Lab, Distributed [Systems and internet/Data Intelligence and] Technologies Lab, Dept. of Information \\ Engineering (DINFO), University of Florence, Italy Via S. Marta, Florence, Italy \\ Correspondence to: Valentina Grasso (v.grasso@ibimet.cnr.it)
}

Received: 17 January 2017 - Accepted: 13 March 2017 - Published: 4 April 2017

\begin{abstract}
During emergencies, an increasing number of messages are shared through social media platforms, becoming a primary source of information for lay people and emergency managers. Weather services and institutions have started to employ social media to deliver weather warnings even if sometimes this communication lacks in strategy. In Twitter, for example, hashtagging is very important to associate messages with certain topics; in recent years, codified hashtagging is emerging as a practical way to coordinate Twitter conversations during emergencies and quickly retrieve relevant information. In 2014, a syntax for codified hashtags for weather warning was proposed in Italy: a list of 20 hashtags, realized by combining \#allertameteo (weather warning) + XXX, where final letters code the regional identification. This contribution presents a monitoring of Twitter usage of weather warning codified hashtags in Italy (since July 2015) and an analysis of different contexts. Twitter messages were retrieved using TwitterVigilance, a multi-users platform to crawl Twitter data, collect and store messages and perform quantitative analytics, about users, hashtags, tweets/retweets volumes. The Codified Hashtags data set is presented and discussed with main analytics and evaluation of regional contexts where it was successfully employed.
\end{abstract}

\section{Introduction}

Social media have proved to be essential sources of information during disasters. Many studies analyzed how social networking sites (SNS) like Facebook and Twitter have been employed during natural hazards like earthquakes (Yates and Paquette, 2011; Smith, 2010), wild fires (Sutton et al., 2008; Merrifield and Panechar, 2012), floods (Starbird et al., 2010; Vieweg et al., 2010; Bruns and Burgess, 2014), hurricanes (Procopio and Procopio, 2007; Hughes et al., 2014). People use social media in disasters for a broad range of reasons, as also recognized by recent studies (Fraustino et al., 2012): to have timely information that no other media can provide (Kavanaugh et al., 2012; Kodrich and Laituri, 2011); to receive unfiltered information (Liu et al., 2013); to offer and search help and organize emergency relief (Starbird and Palen, 2011; Horrigan, 2005); to seek and offer emotional support (Procopio and Procopio, 2007; Stephens and Malone, 2009; Sutton et al., 2008). Social media like Twitter may contribute to enhance situational awareness during disasters (Ireson, 2009; Vieweg et al., 2010). The amount of information exchanged online can be overwhelming making it difficult to retrieve relevant information. In Twitter the use of hashtags tends to reduce this effect. Hashtags are words (or any alphanumeric string) prefixed by the symbol \# that are used in Twitter as message label. Hashtags are important to coordinate public discussion and information sharing (Bruns and Burgess, 2011). Hashtags may emerge spontaneously or may be created ad hoc by users or by organizations as an attempt to create communities of users who discuss around a topic. In recent years the use of codified hashtags emerged as an issues in the field of emergency manage- 
ment, as proved by the publication "Hashtags Standards For Emergencies" (OCHA, 2014). The publication suggests the adoption of a codified syntax to generate hashtags during disasters. In Italy, during 2014, a set of codified hashtags to use on Twitter during weather warnings was proposed. It is a list of 20 hashtags realized by combining \#allertameteo (weather warning) $+\mathrm{XXX}$, where final letters code the regional identification. The regional reference is due to the organization of the Italian civil protection system based on the Regions (Miglietta and Rotunno, 2016; Visconti and Marzano, 2008). Widespread of codified hashtags had only been based on the commitment of local institutions, weather services or citizens to improve communication during disasters. The first consistent use of a codified hashtag is dated November 2013, during Sardinia floods (Parisi et al., 2014). In that case it was a completely user driven adoption, as institutional communication on social media was generally missing. In Tuscany, instead, it was the regional weather service, Consorzio LaMMA, to firstly adopt the codified hashtag on January 2014. Hashtag use was explained in the Social Media Policy and its adoption was prompted when weather warnings were issued. In other regional contexts codified hashtagging approach was employed firstly by citizens. In this work, we present an analysis of one year monitoring of codified hashtags to assess if and where the proposal was successful and hashtags have been adopted.

\section{Methods}

To monitor, retrieve and store all tweets containing the codified hashtags we used the TwitterVigilance platform, developed by DISIT Lab of University of Florence. TwitterVigilance is a tool for multi-users collection of tweets and fast statistical analysis (http://www.disit.org/tv). TwitterVigilance is based on the concept of "Twitter channel" defined as a set of simple and complex search queries performed on Twitter platform via crawler. Complex channels may consist of tens of queries, following the search query syntax of Twitter APIs, obtained by combining keywords, users IDs, hashtags, citations with some operators (e.g., And, Or, From).

It is worth to mention that Twitter API do not guarantee the retrieval of the $100 \%$ of published tweets. Both Streaming API and Search API results are limited by Twitter's rate limits. Such limitations may pose problems to tweets retrieval for critical events where millions of messages are published. Even if this is not the case of our study, we underline that TwitterVigilance has a number of metrics to assess the efficiency of tweets retrieval at the level of single channel. One of these is linked to the estimation of retweets with respect to tweets collected. When a retweet is retrieved, if the reference tweet is missing in the channel the latter is requested and obtained $99.5 \%$ of the time. For limited volume channels this allows to have $100 \%$ of efficiency in recall, and for medium/large channels (over 5 million tweets) the $98 \%$ of efficiency.

A set of monitoring channels was created to retrieve and store all tweets containing at least one of the 20 hashtags and other tweets useful to strengthen research assessment. The main channel is the "Codified Hashtags" (CH) channel where tweets are retrieved following a multiple query parameter corresponding to the list of codified hashtags: \#allertameteoPIE (Piedmont); \#allertameteoVDA (Valle d'Aosta); \#allertameteoLIG (Liguria); \#allertameteoLOM (Lombardia); \#allertameteoVEN (Veneto); \#allertameteoTAA (Trentino Alto Adige); \#allertameteoFVG (Friuli Venezia Giulia); \#allertameteoER (Emilia ROmagna); \#allertameteoTOS (Tuscany); \#allertameteoMAR (Marche); \#allertameteoLAZ (Lazio); \#allertameteoUMB (Umbria), \#allertameteoABR (Abruzzo); \#allertameteoMOL (Molise); \#allertameteoCAM (Campania), \#allertameteoBAS (Basilicata); \#allertameteoPUG (Puglia); \#allertameteoCAL (Calbria); \#allertameteoSIC (Sicily); \#allertameteoSAR (Sardegna). Other channels were created to retrieve: tweets related to bad weather conditions; tweets with the hashtag \#weather; tweets sent by users related to commercial and/or public weather services or weather forecasters. Monitoring period started on 1 July 2015 and ended on 30 June 2016. The data volume of the Codified hashtags channel is much smaller compared to that of channels having common-sense words as query parameters (see Fig. 1). The first one is by definition a channel collecting information produced only during high impact events, whereas other channels collect tweets about bad weather in general (1 843095 tweets published about bad weather conditions respect to only 25185 tweets using codified hashtags).

The $\mathrm{CH}$ data set was analyzed for main metrics: activity pattern over time; volume of different tweets typology over time, differentiating by original tweets (original messages sent by user) and retweets; volume of mentions and replies; volume of URLs in tweets; combined metrics like ratio native tweets/retweets. For each data set the number of "active unique users" was also evaluated, defined as the number of unique users sending original tweets. Respect to temporal distribution of messages, we computed an Activity Rate. This is defined as the percentage of days, during the monitored period, in which at least one tweet containing the hashtag was published. Visibility metrics were also calculated. In particular: number of favourited tweets; most retweeted users and most mentioned users (Bruns and Stieglitz, 2014, 2013). Another component of the analysis was to identify categories of engaged users in the different regional contexts. On this purpose we coded manually the data set of active unique users. The aim was to classify users into main categories and accordingly verify their participation and active role in the conversation around the codified hashtags. Coding was performed by manually annotating accounts depending on their affiliation, as declared in the profile description available on Twitter. We considered six classes of unique users deemed as 


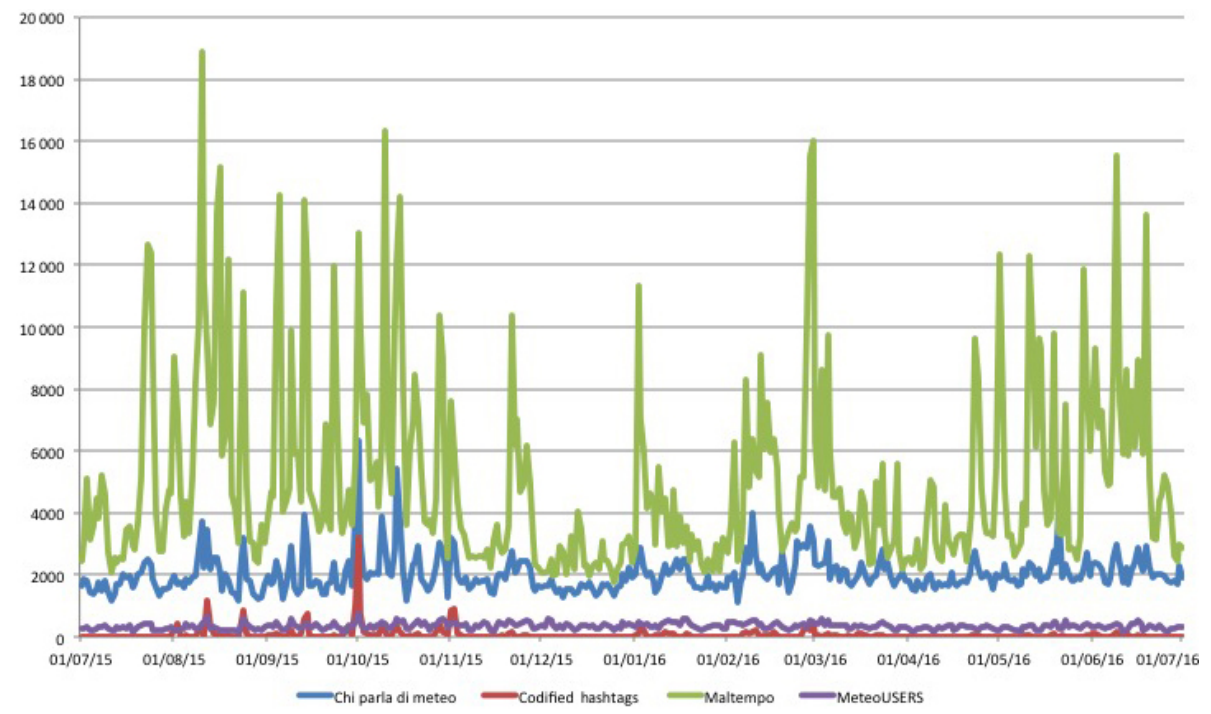

Figure 1. Temporal distribution of the four monitored channels.

relevant for weather related emergency management and fitting the purposes of this work. Considered categories were: Institutions (governments and public agencies); Media (tv, radio, news and online media); Weather (weather forecasting services or weather enthusiast associations); Volunteers-Non Governmental Organization (NGOs active in the field of rescue and emergency management); Citizens (accounts of not affiliated individuals; not belonging to any of the above). The category "BOT" was also considered to identify accounts managed by software agents automatically publishing updates or retweeting users.

\section{Results}

During the monitored period a total amount of 25185 tweets was collected in the Codified Hashtags channel. Native tweets were 7569 and retweets were 17616 , corresponding to the $70 \%$ of retrieved messages. This high retweeting rate is in line with previous studies which recognized it as a typical pattern of social media use during disasters (Bruns and Highfield, 2012; Grasso and Crisci, 2016). Tweets were published by 6674 Unique Users but only $21 \%$ of them were true "Active users", as shown by Table 1 . Around $80 \%$, instead, participated only by sharing tweets. The majority of retrieved messages was related to few high impact weather events occurred in summer and fall 2015. The highest daily peak of the channel was reached on 1 October 2015, during Sardinia floods, with 3189 tweets collected by TwitterVigilance Codified Hashtags channel.

\subsection{Most used hashtags and pattern of use}

Looking at the most used codified hashtags it is very clear that few hashtags have been thoroughly adopted. As it is
Table 1. Main features.

\begin{tabular}{ll}
\hline Total tweets & 25185 \\
Native tweets & 7569 \\
Retweets (RT) & 17616 \\
Unique users & 6674 \\
Active users on total & 1402 \\
Active users \% on total & $21 \%$ \\
\hline
\end{tabular}

showed in Fig. 2, where few long bars (high occurrence) are followed by many shorter ones (low occurrence). During the monitored period, in the majority of regional contexts codified hashtags were poorly adopted or not adopted at all. Among the regions lacking in usage there are small ones, with limited geographic extension and scarce population, but also major Italian Regions like Lazio, Lombardia, Campania or Puglia where the data showed that codified hashtag was not employed.

Considering this study, the most used codified hashtags are:

1. \#allertameteoTOS (\#TOS), that is the top one with 7841 tweets collected in the monitored period and 1448 unique users;

2. \#allertameteoSAR (\#SAR), the second one with 5977 tweets: but it counts on the higher numbers of unique users 2302 ;

3. \#allertameteoCAL (\#CAL), that is the third one with 3549 tweets and 1678 unique users;

4. \#allertameteoLIG (\#LIG), with 3154 tweets collected in the monitored period and 774 users; 
Codified hashtags total tweets (01/07/2015-30/06/2016)

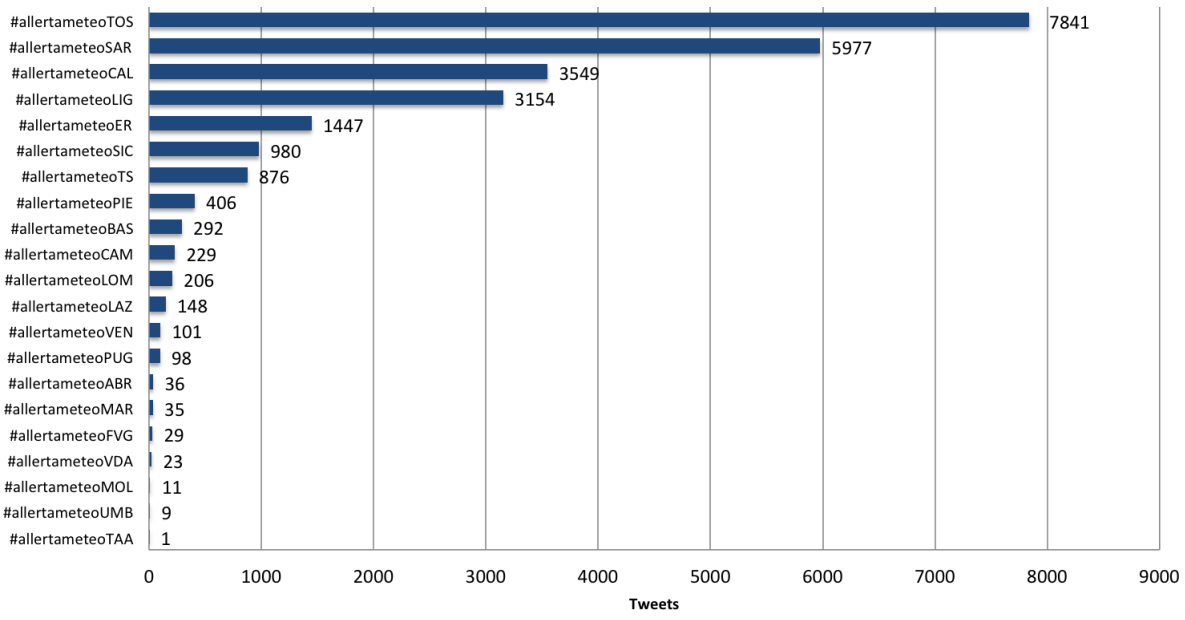

Figure 2. Number of tweets published for each codified hashtag.

5. \#allertameteoER (\#ER), with 1447 tweets collected in the monitored period and 479 users;

6. \#allertameteoSIC (\#SIC), with 980 tweets collected in the monitored period and 403 users.

As shown in Table 2, Tuscany, Sardinia and Calabria are the regions where the codified hashtag was more adopted. The three contexts show different patterns of use. While in Tuscany regional codified hashtag (\#TOS) gained the greater number of occurrences (more tweets in the given period), Sardinia (\#SAR) is the region were unique users were the most, more people engaged. Sardinia and Calabria showed also higher retweets occurrence (79 and $80 \%$ of total tweets), compared to \#TOS, but a lower publication rate per authors, less than 3 tweets per author in \#SAR and \#CAL, compared to more than 10 tweets per unique author in Tuscany. Activity Rate as well varied greatly: with a $70 \%$ of active days in Tuscany, compared to 24 and $29 \%$ in Calabria and Sardinia. For Sardinia and Calabria most of the tweets have been published along a short period of time characterized by high impact weather events. The two regions were in fact theater of devastating floods: 1 October 2015 in Olbia, Sardinia, and 24 August 2015 in Rossano, Calabria. On the contrary, the amount of tweets in Tuscany is the outcome of a more regular use of the hashtag during the whole monitored period, as proven by the activity rate at almost $70 \%$. The data sets of codified hashtag in Liguria (\#LIG), Sicily (\#SIC) and Emilia Romagna (\#ER) present a suitable number of tweets, sign of adoption but less diffused use. The ratio of tweets per user is around 5 in \#ER and 4 in \#SIC and \#LIG; activity rate is around $30-35 \%$ for \#LIG and \#ER but only $11 \%$ in \#SIC. These results confirm what reported by Bruns and Burgess (2011) about the role played by hashtags in the formation of ad hoc publics. These networks of people or communities
Table 2. Main metrics for the six most used hashtags.

\begin{tabular}{lrrrrr}
\hline & Tweets & Users & $\begin{array}{c}\text { Activity } \\
\text { rate }\end{array}$ & RT \% & $\begin{array}{r}\text { TW/ } \\
\text { user }\end{array}$ \\
\hline \#SAR & 5977 & 2302 & $29 \%$ & $79 \%$ & 3 \\
\#CAL & 3549 & 1678 & $24 \%$ & $80 \%$ & 3 \\
\#TOS & 7841 & 1448 & $69 \%$ & $60 \%$ & 10 \\
\#LIG & 3154 & 774 & $30 \%$ & $67 \%$ & 4 \\
\#ER & 1447 & 479 & $35 \%$ & $65 \%$ & 5 \\
\#SIC & 980 & 403 & $11 \%$ & $69 \%$ & 4 \\
\hline
\end{tabular}

can be ephemeral and arise in response to emergencies and crises, like in the case of Sardinia and Calabria, or they can be more stable, like in the case of Tuscany. In Sardinia, as it is shown also in next section, the use of the codified hashtag was driven by citizens and the role of institutions was only marginal and secondary. In Tuscany, on the other hand, institutions had a primary role in the hashtag diffusion as they used it every time a weather warning was issued.

Next section on users and contexts may give more insights to explain this difference.

\subsection{Users and contexts}

To explain the difference in use we examined the typology of active unique users engaged in the hashtags communities. On this purpose within the sub set of six most used codified hashtags (\#TOS, \#LIG, \#SAR, \#SIC, \#LIG, \#ER) we selected the first 100 most active unique users, those contributing with more original tweets. Top 100 authors of the data set were manually annotated in different categories to better describe the channel and to identify the communication pattern of different users. Authors were classified into 
Table 3. Geo annotation of 100 most active users (authors and mentions).

\begin{tabular}{lrr}
\hline $\begin{array}{l}\text { Regional } \\
\text { annotation }\end{array}$ & $\begin{array}{r}\text { Unique } \\
\text { authors }\end{array}$ & $\begin{array}{r}\text { Mentioned } \\
\text { users }\end{array}$ \\
\hline Tuscany & 37 & 21 \\
Liguria & 12 & 14 \\
National & 11 & 24 \\
Sardinia & 11 & 14 \\
Emilia Romagna & 8 & 8 \\
Calabria & 4 & 8 \\
undefined & 4 & 3 \\
Lombardy & 3 & 2 \\
Friuli V. G. & 2 & 2 \\
Piedmont & 2 & 1 \\
Sicily & 2 & 2 \\
Basilicata & 1 & 0 \\
Campania & 1 & 0 \\
Lazio & 1 & 1 \\
Puglia & 1 & 0 \\
\hline
\end{tabular}

six categories, as explained in Sect. 2. The accounts of top 100 users were also manually coded for regional attribution (see Table 3). Almost $37 \%$ of top users resulted to be from Tuscany. This may be considered a further element attesting that the adoption of the codified hashtag in Tuscany was more remarkable. Among the other users, around $12 \%$ resulted to be from Liguria and $11 \%$ for Sardinia. Accounts with a nation-wide dimension were $11 \%$ and they were mainly Media accounts and some commercial forecasting service accounts. They were also the most mentioned users (24\%) in the top 100 authors (Table 4). As second step we annotated those 100 unique users following the identified categories. As showed in Table 4, Institutions revealed to be the most active (27\%), followed by Citizens ( $26 \%$ ) and Media (18\%). Half of these very active Institutional accounts were from Tuscany. Institutions engagement around the codified hashtag in Tuscany sustained the formation of a more stable community around the \#allertameteoTOS. In this sense it was important the engagement of Tuscany weather service account (@flash_meteo) that promoted and widespread the use of the codified hashtag for weather warnings. Regularly adopted in warnings, codified hashtag spread to local institutions and volunteers in charge of emergency management and was integrated into official alert communications. Institutional use boosted $\mathrm{CH}$ adoption by media and citizens accounts.

This pattern of communication, that emerged only in Tuscany, appears to be a case of "regular use", as also confirmed by the highest Activity Rate (69\%), by the highest number of tweets published during the monitored period and by the highest ratio of tweets per user (10). Institutions were the key players leading to the formation of a more stable community of users. In Sardinia, instead, the hashtag adoption followed a bottom-up approach and the network of users was more acci-
Table 4. Users' category of top 100 accounts (as authors and mentions).

\begin{tabular}{lrr}
\hline $\begin{array}{l}\text { Users } \\
\text { category }\end{array}$ & $\begin{array}{r}\text { Unique } \\
\text { authors }\end{array}$ & $\begin{array}{r}\text { Mentioned } \\
\text { users }\end{array}$ \\
\hline Institutions & 27 & 41 \\
Citizens & 26 & 22 \\
Media & 18 & 21 \\
NGO & 14 & 5 \\
Weather & 12 & 11 \\
BOT & 1 & - \\
Not identified & 2 & - \\
\hline
\end{tabular}

dental and ephemeral. The codified hashtag was proposed by users and it get spread due to single influencers and media accounts. Institutions did not showed a specific hashtag strategy during the emergency or afterwards. Like what happened in Calabria, the hashtag adoption revealed a kind of "burst use" related to exceptional and isolated situations linked to the occurrence of a disaster. In these two case, in fact, we find the highest number of engaged users and high volumes of tweets per day, but only during the limited period of the emergency. Activity rate was in fact around $25-30 \%$ during the whole monitored period. In other contexts hashtag use was much lees rooted. In Emilia Romagna and Liguria activity rate was about $35 \%$, an indicator of a weak engagement by the community; temporal distribution of messages, though, was more regular respect to Sardinia and Calabria. Institutions were not fully engaged in this adoption but they started, especially in Emilia Romagna. In Liguria the regional weather forecasting service created a Twitter account deputed to weather warnings. The account publishes automated updates about weather alerts but tweets do not include any specific hashtag. In Sicily adoption appears even weaker, with only $11 \%$ of activity rate. In other contexts hashtags were poorly used during the monitoring period; contexts like Piedmont, Basilicata and Lazio showed a still timid use. In all these cases, institutional communication on Twitter appeared almost missing. When institutions' role is missing, the codified hashtag does not spread. In some cases citizens may take the lead in communication practices with the aim of organizing the community efforts to tackle the emergency during the response and recovery phase. However, a bottom-up approach does not allow to work on the preparedness phase, which needs to be coordinated and organized by the deputy institutions and has to rely on stable network of users.

\section{Conclusions}

Analyzing the data collected with the help of the TwitterVigilance platform during the monitored period (from July 2015 to June 2016) it emerges that only six out of the twenty proposed codified hashtags for weather warning showed a sig- 
nificant adoption. Highest number of tweets was reached by \#TOS, which accounts for $30 \%$ of the whole Codified Hashtags data set.

Following Bruns and Burgess (2011) idea that hashtags may sustain the formation of ad hoc publics, we may say that in most of the contexts codified hashtags only created "ephemeral" communities, arising in response to an emergency; in Tuscany, instead, Institutions engagement sustained the creation of a more stable network of users, a sort of long-term community of practice deputed to spread weather warnings, share advice and recommendations as to be prepared in case of emergency.

The analysis of regional contexts highlighted different pattern of usage. Tuscany appears to be a case of "regular use". In Tuscany codified hashtag was actually adopted and institutions had a primary role in building the hashtag-community. Sardinia and Calabria revealed on the contrary a kind of "burst use" related to the occurrence of a disaster. Twitter activity around the hashtag is triggered by extraordinary circumstances and is largely sustained by Citizens. Those are also the contexts where Institutions appear less engaged in hashtag adoption and in Twitter in general. In other Regions the codified hashtag for weather warning showed to be poorly used, Emilia Romagna, Liguria, Sicily and Piedmont, or never used, Campania, Lombardia, Veneto ecc. Many different reasons could help explaining this diversity, starting from population disparity, geographical digital divide, difference in social media use in urban and rural contexts. One reason could also be ascribable to different regional climatic conditions. Regions on the Tyrrhenian Sea, like Liguria, Tuscany, Calabria, Sardinia, Sicily are more exposed to exceptional rains and consequent flash floods or major flooding. In these contexts, institutions and citizens probably have found themselves to face more often this kind of emergencies and turned to social media as a new way to cope with high impact weather.

Code availability. Code used for Twitter analytics is available at: https://github.com/valenitna/EMS_codified.

Data availability. Data are available at: https:/github.com/ valenitna/EMS_codified.

Competing interests. The authors declare that they have no conflict of interest.

Disclaimer. The article reflects only the authors' view and the European Commission is not responsible for any use that may be made of the information it contains.
Acknowledgements. This article is part of Phd research work of Valentina Grasso. It represents also one of the several results of the CARISMAND project which has received funding from the European Union's Horizon 2020 research and innovation programme under grant agreement No. 653748.

Edited by: D. Cotgrove

Reviewed by: F. Comunello and one anonymous referee

\section{References}

Bruns, A. and Burgess, J. E.: The use of Twitter hashtags in the formation of ad hoc publics, in: Proceedings of the 6th European Consortium for Political Research (ECPR) General Conference 2011, 25-27 August 2011, Reykjavìk, Iceland, 2011.

Bruns, A. and Burgess, J. E.: Crisis communication in natural disasters: The Queensland floods and Christchurch earthquakes, Twitter Soc., 89, 373-384, 2014.

Bruns, A. and Highfield, T.: Blogs, Twitter, and breaking news: the produsage of citizen journalism, in: Produsing Theory in a Digital World: The Intersection of Audiences and Production in Contemporary Theory, Vol. 80, Peter Lang Publishing Inc., 15-32, 2012.

Bruns, A. and Stieglitz, S.: Towards more systematic Twitter analysis: Metrics for tweeting activities, Int. J. Social Res. Methodol., 16, 91-108, 2013.

Bruns, A. and Stieglitz, S.: Metrics for understanding communication on Twitter, Twitter Soc., 89, 69-82, 2014.

Fraustino, J. D., Liu, B., and Jin, Y.: Social media use during disasters: a review of the knowledge base and gaps, National Consortium for the Study of Terrorism and Responses to Terrorism, 2012.

Grasso, V. and Crisci, A.: Codified Hashtags for Weather Warning on Twitter: an Italian Case Study, PLOS Currents Disasters, doi:10.1371/currents.dis.967e71514ecb92402eca3bdc9b789529, in press, 2016.

Horrigan, J.: Relief donations after Hurricanes Katrina and Rita and use of the Internet to get disaster news, Pew Internet \& American Life Project, Wahington, http://www.pewinternet.org/ / media//Files/Reports/2005/PIP_Katrina.DateMemo.pdf.pdf (last access: January 2017), 2005.

Hughes, A. L., St Denis, L. A., Palen, L., and Anderson, K. M.: Online public communications by police $\&$ fire services during the 2012 Hurricane Sandy, in: Proceedings of the 32nd annual ACM conference on Human factors in computing systems, 26 April1 May 2014, Toronto, Canada, 1505-1514, 2014.

Ireson, N.: Local community situational awareness during an emergency, in: 2009 3rd IEEE International Conference on Digital Ecosystems and Technologies, 1-3 June 2009, Istanbul, Turkey, 49-54, 2009.

Kavanaugh, A. L., Fox, E. A., Sheetz, S. D., Yang, S., Li, L. T., Shoemaker, D. J., Natsev, A., and Xie, L.: Social media use by government: From the routine to the critical, Govern. Inf. Quart., 29, 480-491, 2012.

Kodrich, K. and Laituri, M.: Making a connection: Social media's key role in the Haiti earthquake, J. Commun. Comput., 8, 624627, 2011. 
Liu, B. F., Jin, Y., and Austin, L. L.: The tendency to tell: Understanding publics' communicative responses to crisis information form and source, J. Publ. Relat. Res., 25, 51-67, 2013.

Merrifield, N. and Panechar, M.: Uncertainty Reduction Strategies via Twitter: The 2011 wildfire threat to Los Alamos National Laboratory, in: Proceedings from AEJMC Annual Conference, 9-12 August 2012, Chicago, 2012.

Miglietta, M. M. and Rotunno, R.: An EF3 Multivortex Tornado over the Ionian Region: Is It Time for a Dedicated Warning System over Italy?, B. Am. Meteorol. Soc., 97, 337-344, 2016.

OCHA: Hashtag Standards For Emergencies, Tech. rep., United Nations Office for the Coordination of Humanitarian Affairs, UN OCHA, New York, 2014.

Parisi, L., Comunello, F., and Amico, A.: Social media e comunicazione di emergenza, chap. \#allertameteoSAR: analisi di un hashtag di servizio tra dinamiche di influenza e nuove forme di engagement, Guerini Editore, Milano, 2014.

Procopio, C. H. and Procopio, S. T.: Do you know what it means to miss New Orleans? Internet communication, geographic community, and social capital in crisis, J. Appl. Commun. Res., 35, 67-87, 2007.

Smith, B. G.: Socially distributing public relations: Twitter, Haiti, and interactivity in social media, Publ. Relat. Rev., 36, 329-335, 2010.

Starbird, K. and Palen, L.: Voluntweeters: Self-organizing by digital volunteers in times of crisis, in: Proceedings of the SIGCHI Conference on Human Factors in Computing Systems, 7-12 May 2011, Vancouver, Canada, 1071-1080, 2011.
Starbird, K., Palen, L., Hughes, A. L., and Vieweg, S.: Chatter on the red: what hazards threat reveals about the social life of microblogged information, in: Proceedings of the 2010 ACM conference on Computer supported cooperative work, 6-10 February 2010, Savannah, USA, 241-250, 2010.

Stephens, K. K. and Malone, P. C.: If the organizations won't give us information: The use of multiple new media for crisis technical translation and dialogue, J. Publ. Relat. Res., 21, 229-239, 2009.

Sutton, J., Palen, L., and Shklovski, I.: Backchannels on the front lines: Emergent uses of social media in the 2007 southern California wildfires, in: Proceedings of the 5th International ISCRAM Conference, Washington, D.C., 624-632, 2008.

Vieweg, S., Hughes, A. L., Starbird, K., and Palen, L.: Microblogging during two natural hazards events: what twitter may contribute to situational awareness, in: Proceedings of the SIGCHI conference on human factors in computing systems, 10 15 April 2010, Atlanta, USA, 1079-1088, 2010.

Visconti, G. and Marzano, F. S.: An independent overview of the national weather service in Italy, B. Am. Meteorol. Soc., 89, 1279 , doi:10.1175/2008BAMS2372.1, 2008.

Yates, D. and Paquette, S.: Emergency knowledge management and social media technologies: A case study of the 2010 Haitian earthquake, Int. J. Inform. Manage., 31, 6-13, 2011. 